\title{
Applying process integration methods to target for electricity production from industrial waste heat using Organic Rankine Cycle (ORC) technology
}

\author{
Roman Hack1 ${ }^{1, *}$, Simon Harvey ${ }^{1}$ \\ ${ }^{1}$ Chalmers University of Technology Göteborg, Sweden \\ *Corresponding author: Tel: +46 31772 3861, Fax: +46 31 821928, E-mail: roman.hackl@chalmers.se
}

\begin{abstract}
This paper presents the results of an investigation of power production from low temperature excess process heat from a chemical cluster using Organic Rankine Cycle (ORC) technology. Process simulations and process integration methods including Pinch Technology and Total Site Analysis (TSA) are used to estimate the potential for electricity production from excess heat from the cluster. Results of a previous TSA study indicate that ca. $192 \mathrm{MW}_{\text {heat }}$ of waste heat are available at $84{ }^{\circ} \mathrm{C}$ to $55^{\circ} \mathrm{C}$, a suitable temperature range for ORC applications. Process streams especially suitable for ORC power production are identified. Simulation results indicate that $14 \mathrm{MW}_{\text {heat }}$ of waste heat are available from a PE-reactor, which can be used to generate ca. $1 \mathrm{MW}_{\mathrm{el}}$. Costs of electricity production calculated range from $70 \mathrm{to} 147 € / \mathrm{MWh}$ depending on the cost for ORC integration. Economic risk evaluation indicates that pay-back periods lower than 4.5 years should not be expected at the electricity price and RES-E support (a European support system for renewable electricity) levels considered in this study. $\mathrm{CO}_{2}$ emission reductions of up to 5900 tonnes/year were estimated for the analysed case.
\end{abstract}

Keywords: Organic Rankine Cycle, Process integration, Total site analysis, Waste heat recovery.

\section{Introduction}

\subsection{Background}

Growing awareness about the greenhouse effect combined with limited fossil fuel resources provide clear incentives for implementing energy savings measures and achieving $\mathrm{CO}_{2}$ emission reductions in industry. One example to increase energy efficiency is the conversion of low temperature excess process heat into electricity using Organic Rankine Cycle (ORC) technology. The objective of this paper is to assess the potential for electric power generation from low temperature excess process heat at the chemical cluster in Stenungsund, Sweden. Results from a previously performed total site analysis [1] are used to determine the overall amount and the temperature levels of net excess heat from the cluster. Net excess heat is defined as heat that is available after all opportunities for process integration have been exploited and for which no other alternative use is available. Simulation of a selected ORC power cycle was conducted so as to quantify the power output and the overall performance of the system. A preliminary economic evaluation of a selected configuration is presented based on the simulations, supplier/literature data for ORC technology, engineering assumptions for ORC integration and scenarios for assessing profitability and carbon balances of energy investments [2]. The work aims at providing a basis for future projects to optimize energy usage and consequently lower costs and $\mathrm{CO}_{2}$ emissions from the cluster.

\subsection{ORC Technology}

ORC is a technology to generate electricity from low temperature heat sources. Unlike in a conventional steam Rankine cycle, a low boiling point organic fluid is used as working fluid. In low temperature applications this technology offers advantages over conventional Rankine Cycles, and a higher heat recovery (efficiency) can be achieved [3]. ORC systems are mainly used in geothermal, solar and industrial waste heat recovery applications. Figure 1 illustrates the working principle of an ORC. The working fluid is pumped from a lower pressure level 
(state 1) to a higher (state 2). Between states 2 and 3 the fluid exchanges heat with a waste heat stream in a heat exchanger and is evaporated. Contrary to Rankine cycle technology, the working fluid is usually not superheated after the evaporator. The vapour is then expanded in a turbine (state 4), which is connected to a generator to produce electricity. The expanded vapour is condensed by transferring heat to a cooling medium in the condenser (state 1). The cooling can be achieved by air coolers, cooling water or other heat sinks.

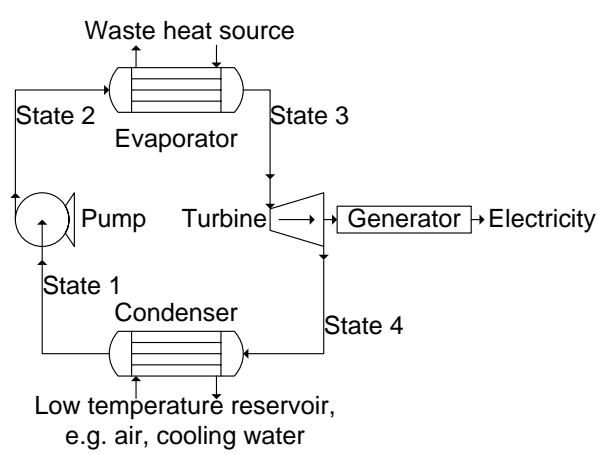

Fig. 1. Working principle of a simple ORC
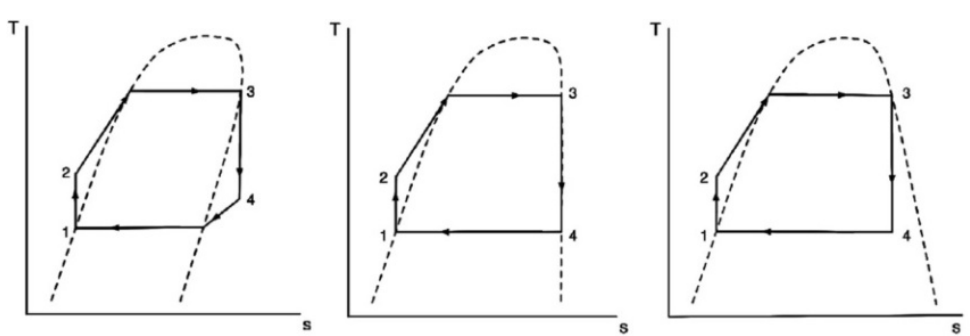

Fig. 2. Characteristic T-S process ORC diagrams for "dry", "isentropic" and "wet"-fluids [4]

The choice of the working fluid strongly influences the efficiency and economy of an ORC system. Working fluids can be divided into three different groups according to their behaviour in the thermodynamic cycle. Figure 2 shows the characteristic T-S diagrams for the three different types of working fluids. "Wet" fluids have a negative slope in the saturation vapour curve. Expansion in the turbine occurs entirely in the two-phase state, and the liquid fraction of "wet" fluids increases. The liquid droplets that form can cause blade erosion damage to the turbine. Condensation is easiest avoided by superheating of "wet" fluids. "Dry"-fluids have a positive slope (left), which means they do not condense during expansion since the degree of superheat increases as the expansion proceeds. Examples of such working fluids include organic substances such as benzene and refrigerants. The third group is "isentropic" fluids with quasi-vertical saturated vapour curves. Since the purpose of an ORC is to recover low temperature heat for electricity production, superheating is not appropriate. Therefore the working fluids used are either "dry" or "isentropic" [5]. Moreover, water has the disadvantage of having a higher specific volume compared to organic working fluids. This increases the size of the turbine, the height of the turbine's last stage blades and pipe diameters [3]. The working fluid should be selected with care so as to achieve a good match with the heat source characteristics and also the available cooling facilities. The following properties should also be considered: high thermal stability at the given operating conditions, low specific volume, low cost, low toxicity, low Ozone Depletion Potential (ODP) and low Global Warming Potential (GWP). The choice has to be based on careful analysis of the given conditions [6].

\subsection{Results from total site analysis (TSA)}

In a previous work the cluster was analyzed using TSA methodology [1]. The method is based on pinch technology and aims for integration of the heating and cooling demands of the different individual processes at a given site with a common utility system. In this way the amounts of hot utility generated and used by the combined individual processes, the amount of heat recovered in a common hot utility system, and the cogeneration potential can be determined [1]. The previous study [1] showed that the combined heating demand of process plants within the cluster is $442 \mathrm{MW}$ of which $320 \mathrm{MW}$ can be covered by heat recovery within the cluster, assuming that no changes are made to existing process utility levels. The 
other $122 \mathrm{M} \mathrm{W}$ must be covered by hot utility, mostly in the form of boiler steam. Furthermore, the previous TSA study also showed that by making improvements to the overall utility system which enable increased energy collaboration between the companies it is possible to increase the amount of heat recovery at the site from $320 \mathrm{MW}$ to $449 \mathrm{MW}$. As a result, boiler utility steam is no longer necessary. In addition a net surplus of $7 \mathrm{MW}$ steam is achieved. The cooling demand of the cluster is then $506 \mathrm{MW}$ at temperatures up to $84{ }^{\circ} \mathrm{C}$.

These results are used in the present study to determine the maximum potential for power generation from low temperature excess heat within the cluster, using ORC technology. Because of the relatively low efficiency of low temperature heat-to-electricity conversion it is appropriate to only utilise net excess heat that cannot be utilised in another way [7]. The maximum potential for heat available for power production is estimated using TSA. Within the cluster available heat is estimated at $\mathrm{Q}_{\mathrm{ORC}}=192 \mathrm{MW}_{\text {heat }}$ at temperatures between $84^{\circ} \mathrm{C}$ and $55^{\circ} \mathrm{C}$.

\section{Methodology}

\subsection{Heat source selection}

From the inventory of the excess process heat available, a selection is made to focus on streams with loads and temperature levels interesting for power generation and for which there is no alternative use. This temperature range was determined in a previous TSA study. The maximum heat source temperature for excess heat from the cluster is $84^{\circ} \mathrm{C}$. The minimum allowable heat source temperature was selected as $55^{\circ} \mathrm{C}$ in order to achieve acceptable Carnot conversion efficiency values. Supplier information also confirmed this value of lower temperature limit [8].

\subsection{ORC simulation}

Literature data about ORC cycles only provided information about approximate efficiency values. Furthermore, it was necessary to evaluate different working fluids depending on the process conditions in order to achieve maximum efficiency. Therefore a simple ORC cycle was simulated in HYSYS. The cycle includes a pump, an evaporator, a turbine and a condenser. The tested working fluids are R134a, Propane, 1-Butene, Butane and Pentane as they are typical fluids for ORC applications at low temperature levels. The results are used as input for the economic evaluation.

\subsection{Cost estimations}

To determine the basic investment costs of the unit, the turbine capacity (in $\mathrm{kW}$ ) is taken as the indicative size of the new unit. The equipment costs of a reference ORC-unit are estimated based on published data for a reference geothermal power plant located in Altheim, Austria with a capacity of $1 \mathrm{MW}_{\mathrm{el}}$ [9]. The equipment cost of this reference ORC-unit is $1.58 \mathrm{M} €$ (in 2000). This cost was updated using the Chemical Engineering Plant Cost Index (CEPCI) for 2010 and 2000, i.e. an update factor of 1.376 [10]. Furthermore, a scaling factor of 0.7 (widely used for electricity production) was used for estimating the investment costs of differently sized units [11]. The installed cost of the ORC unit can thereafter be calculated based on published cost data for an ORC plant in Lienz, Austria with an installation cost factor of 1.32 [12], which covers planning, installation and grid connection costs. Not included are the costs of integration in the considered process plant.

The costs for integrating the ORC into the process plant vary depending on the situation onsite, the process fluid, the location of the ORC-unit and other factors. Three examples of 
projects presented by the ORC manufacturer Turboden [13] indicate integration cost factors ranging from 1.7 to 2.6. All projects include a thermal oil cycle which collects the heat from the waste heat source and delivers it to the ORC unit. For this reason those systems are more complicated and expensive than systems where the process stream is used directly, which might be the case for integration with a chemical cluster. Therefore integration cost factors from 1.1 to 2.6 were considered in this work. The annuity method is used for determining the annualized investment costs $\mathrm{I}_{\text {total annualized capital cost }}$ ) which are used to estimate the net Cost of Electricity $(\mathrm{CoE})$ generation for the ORC plant. The assumed internal interest rate is $11 \%\left(\mathrm{i}_{\mathrm{r}}\right)$. The economic lifetime $\left(\mathrm{t}_{\mathrm{e}}\right)$ is assumed to be 15 years, as this is typical for CHP plants based on ORC technology [12]. The corresponding annuity factor is 0.14 . Cost data for annual operating costs are assumed to be $3 \%$ of the installed costs of the ORC plus the personnel costs $(400 \mathrm{~h} / \mathrm{yr}$ á $30 € / \mathrm{h})$ [12]. The CoE are calculated by Eq. (1)

$\mathrm{CoE}=\frac{\mathrm{I}_{\text {total annualized capital cost }}+\text { Annual operating costs }}{\text { Annual electricity production }}$

$\mathrm{CoE}$ can then be compared with scenario values for electricity purchased from the grid. The economic value of the electricity produced is based on avoided costs of purchasing electricity. Five different grid electricity price scenarios are analysed, see Table 1.

In order to discuss the economic risk of investment in an ORC unit, the payback period for a new ORC investment is also calculated. The total annual savings take into account the avoidance of electricity purchased (equal to net power output of ORC) and the electricity saved by less cooling water pumping ( $2.5 \%$ of net power output of ORC). When producing electricity from waste heat, which otherwise is cooled by cooling water, part of the cooling is saved. The main part of the cooling costs is the pump work in the cooling water system. In this study it is assumed that for each avoided MW of cooling, $0.025 \mathrm{MW}_{\mathrm{el}}$ are saved. These cost savings are calculated with the assumed electricity price and included in the annual cash flow to calculate the payback period (see below). An annual running time of $8000 \mathrm{~h}$ per year is assumed. The pay-back period for the ORC investment can then be calculated according to Eq. (2).

Pay - back period $=\frac{\mathrm{I}_{\text {total ORC }}}{(\text { Annual savings }- \text { Annual operating costs) }}$

The scenarios were generated using the ENPAC tool, developed with the purpose of evaluating the performance of future or long-term energy investments at industrial sites using consistent scenarios. Scenarios chosen in this study include the current electricity price and two scenarios (high/low) for the years 2020 and 2030. RES-E support is currently not granted in Sweden for electricity production from waste heat with fossil origin. In this study both case (with and without support) will be shown in order to show its influence on the overall economic performance of ORC investments. By using a number of different scenarios that outline possible cornerstones of the future energy market, robust investments can be identified and the climate benefit can be evaluated. To obtain reliable results, it is important that the energy market parameters within a s cenario are consistent. Consistent scenarios can be achieved by using a tool in which the energy-market parameters (e.g. energy prices and energy conversion technologies) are related to each other [14]. Table 1 shows the electricity prices, support levels for "green" electricity generation and $\mathrm{CO}_{2}$ emissions from electricity production from the assumed long term marginal electricity production. 
Table 1. Electricity prices, support for green electricity, $\mathrm{CO}_{2}$ emissions from electricity production and marginal long term electricity production for the five scenarios [2]

\begin{tabular}{|c|c|c|c|c|c|c|}
\hline Scenario & & 1 & 2 & 3 & 4 & 5 \\
\hline Year & & 2010 & 2020 & 2020 & 2030 & 2030 \\
\hline Fossil fuel price & & 2010 & Low & High & Low & High \\
\hline $\mathrm{CO}_{2}$ charge & {$[€ /$ ton $]$} & 20 & 15 & 58 & 15 & 58 \\
\hline Electricity price SPOT & {$\left[€ / \mathrm{MWh}_{\mathrm{el}}\right]$} & 51 & 46 & 74 & 45 & 81 \\
\hline RES-E support ${ }^{1}$ & {$\left[€ / \mathrm{MWh}_{\mathrm{el}}\right]$} & 20 & 20 & 20 & 20 & 20 \\
\hline $\begin{array}{l}\mathrm{CO}_{2} \text { emission from electricity } \\
\text { production }\end{array}$ & {$\left[\mathrm{kg} / \mathrm{MWh}_{\mathrm{el}}\right]$} & 770 & 722 & 722 & 679 & 129 \\
\hline $\begin{array}{l}\text { Long term marginal electricity } \\
\text { production }\end{array}$ & & Coal & Coal & Coal & Coal & $\begin{array}{l}\text { Coal, } \\
\text { CCS }\end{array}$ \\
\hline
\end{tabular}

${ }^{\mathrm{I}}$ Premium paid to producers of electricity from renewable energy sources [2]

\section{4. $\mathrm{CO}_{2}$ emissions reduction}

$\mathrm{CO}_{2}$ emissions reduction by electricity produced with an ORC unit is calculated from $\mathrm{CO}_{2}$ emissions data for future long term marginal electricity production in Table 1. It is assumed that electricity from the ORC unit replaces marginal electricity and that the waste heat used for electricity production has no alternative use (in this case the possibility to deliver waste heat to the district heating system close to the cluster is fully exploited).

\section{Results}

\subsection{Heat source selection}

One heat source is chosen as an example to carry out further investigations, including simulation of the ORC unit using HYSYS and economic assessment and calculation of $\mathrm{CO}_{2}$ emissions reduction. The stream chosen is a loop reactor jacket cooling water stream with $\mathrm{T}_{\text {start }}$ and $\mathrm{T}_{\text {target }}$ of $78{ }^{\circ} \mathrm{C}$ and $68{ }^{\circ} \mathrm{C}$, respectively. This results in a Carnot efficiency of $17 \%$. The heat load of the stream is $13970 \mathrm{~kW}$.

\subsection{ORC simulation}

Simulations were carried out with different "dry" fluids appropriate for use in ORC systems. The main results are presented in Table 2. The turbine inlet and outlet pressure is chosen so that the boiling point of the working fluid is matched with the temperature profile of the heat source and the heat sink (cooling water at 20 to $25^{\circ} \mathrm{C}$ ) respectively. Among the five working fluids investigated, butane shows the best net electrical output and electrical efficiency. R134a and Propane are interesting cases, but the cycle needs to operate at higher pressure than the cycle with butane. Lower operating pressure should be preferred as increased pressure implies higher investment costs. Pentane is not suitable as the minimum pressure in the cycle is set to 0 bar(g), to avoid extra costs for vacuum operation. Pentane is more suitable for higher temperature heat sources. Butane has a slightly higher power output and efficiency compared to 1-Butene. The simulation with a mixture of pentane and butane does not show better results than with a single fluid, even though the temperature profiles of heat source and working media match better, which results in less exergy losses during evaporation. High performance is not reached with the mixture as the pressure difference for expansion in the turbine is not sufficient. Pentane limits the maximum and butane the minimum possible pressure in the given case $\left(\Delta \mathrm{T}_{\min }\right.$ of $5 \mathrm{~K}$ in the evaporator and condenser). Butane was retained as working 
fluid for the ORC unit. This cycle has a net electricity output of $958 \mathrm{~kW}$ el $(7.7 \mathrm{GWh} / \mathrm{yr}$ for 8000 hours/yr of operation), with $6.85 \%$ electrical efficiency.

Table 2 Results from the simulation in HYSYS for an ORC unit using loop reactor cooling water heat source

\begin{tabular}{lcccccc}
\hline & R 134a & Propane & 1-Butene & Butane & Pentane & Butane +Pentane \\
\hline $\mathrm{p}_{\text {turb,in }}[\operatorname{bar}(\mathrm{g})]$ & 18.5 & 23 & 7.6 & $\mathbf{6 . 2}$ & 1.45 & 3.5 \\
$\mathrm{p}_{\text {turb,out }}[\operatorname{bar}(\mathrm{g})]$ & 6.7 & 9.8 & 2.5 & $\mathbf{1 . 8}$ & 0 & 0.6 \\
$\mathrm{Q}_{\mathrm{el}, \text { out }}(\mathrm{net})[\mathrm{kW}]$ & 923 & 900 & 948 & $\mathbf{9 5 8}$ & 798 & 950 \\
$\eta_{\mathrm{el}}[\%]$ & 6.6 & 6.4 & 6.8 & $\mathbf{6 . 8 5}$ & 5.7 & 6.8 \\
\hline
\end{tabular}

\subsection{Cost estimation}

The results for the selected heat source stream are presented below. Costs calculations have been performed according to the procedure defined in Section 2.3. Table 3 shows simulation and economic results for the selected waste heat source assuming butane as working fluid

Table 3 Turbine capacity, basic equipment investment costs, installed costs and operating costs

\begin{tabular}{ccccc}
\hline $\begin{array}{c}\text { Turbine } \\
\text { output }[\mathrm{kW}]\end{array}$ & $\begin{array}{c}\text { Net power } \\
\text { output }[\mathrm{kW}]\end{array}$ & $\begin{array}{c}\text { Equipment investment } \\
\text { costs for ORC unit }[€]\end{array}$ & $\begin{array}{c}\text { Investment costs ORC } \\
\text { including installation }[€]\end{array}$ & $\begin{array}{c}\text { Operating } \\
\text { costs }[€ / \mathrm{yr}]\end{array}$ \\
\hline 993 & 958 & 2163489 & 2855806 & 97674 \\
\hline
\end{tabular}

The calculated $\mathrm{CoE}$ range from 70 to $147 € / \mathrm{MWh}$, depending on the integration cost factor, see Figure 3 and Figure 4. The electricity price scenarios in Figure 3 do not include RES-E support. It can be seen that at the current electricity price (Scenario 1: ca. $51 € / \mathrm{MWh}$ ) and without RES-E support, investing in an ORC is not profitable.

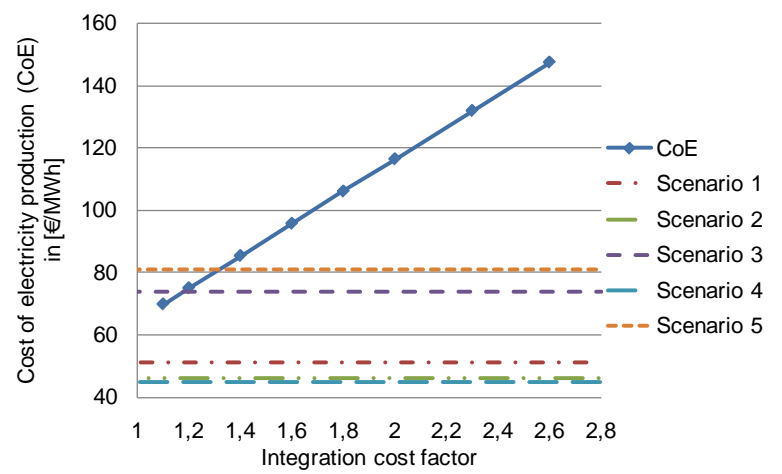

Fig. 3. CoE depending on the integration cost factor (with electricity price scenarios without RES-E support)

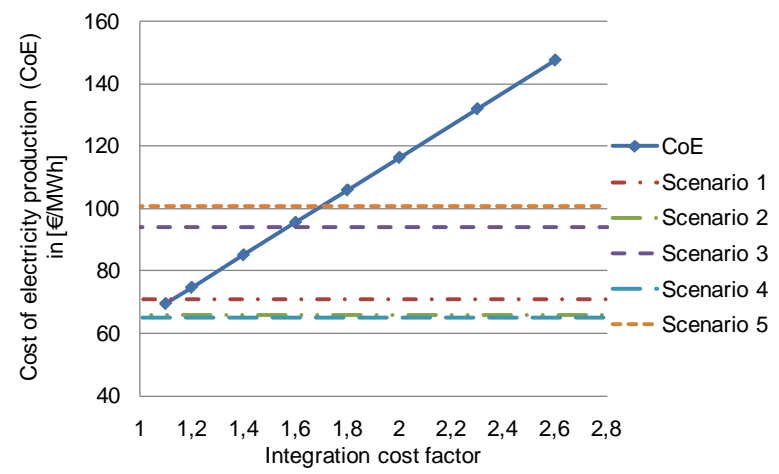

Fig. 4. CoE depending on the integration cost factor (with scenarios including RES-E support)

Without RES-E support, ORC electricity generation is only profitable for the two highest price scenarios (Scenario 3 and 5) considered in this study and at low costs of integration. If RES-E support is granted also more complicated integration is feasible at high electricity prices. At low integration costs even the current electricity price shows a feasible investment. Calculations on the pay-back period of an ORC investment show that without support for electricity production the pay-back period for the lowest costs of integration estimated $(10 \%$ of ORC installed costs) ranges from 5.8 to 12.3 years depending on the electricity price scenario. With RES-E support the pay-back period is decreased for the low integration factor 
case to between 4.5 to 7.7 years. Even if RES-E support is considered, pay-back periods lower than 4.5 years should not be expected for ORC technologies at the electricity price and RES-E support levels considered in this study. On-site electricity production bears lower risks than other investments, as the produced electricity can be used on-site. This might justify longer pay-back periods. The scenarios used in this study include costs for $\mathrm{CO}_{2}$ emissions from fossil-fuel fired power plants. It can also be seen that in the scenarios with low $\mathrm{CO}_{2}$ emission charge (scenario 2 and 4) the costs of electricity production and pay-back period are highest, while high $\mathrm{CO}_{2}$ emissions charge (scenario 3 and 5) shows lower values. Therefore $\mathrm{CO}_{2}$ emissions charge is seen as an important parameter which has a large influence on the profitability of ORC investments.

\section{4. $\mathrm{CO}_{2}$ emissions reduction}

Figure 5 shows the $\mathrm{CO}_{2}$ emissions reduction in the different scenarios when electricity is produced with an ORC unit. It can be seen that the reduction is high if marginal electricity from coal power plants is replaced by electricity from the ORC unit, 5204-5902 tonnes$\mathrm{CO}_{2}$ /year. The least reduction is achieved if marginal electricity is produced in coal power plants with carbon capture and storage (CCS) technology (989 tonnes- $\mathrm{CO}_{2} /$ year). This is the case because the electricity produced with an ORC replaces marginal electricity, which in the $\mathrm{CCS}$ case already has relatively low $\mathrm{CO}_{2}$ emissions.

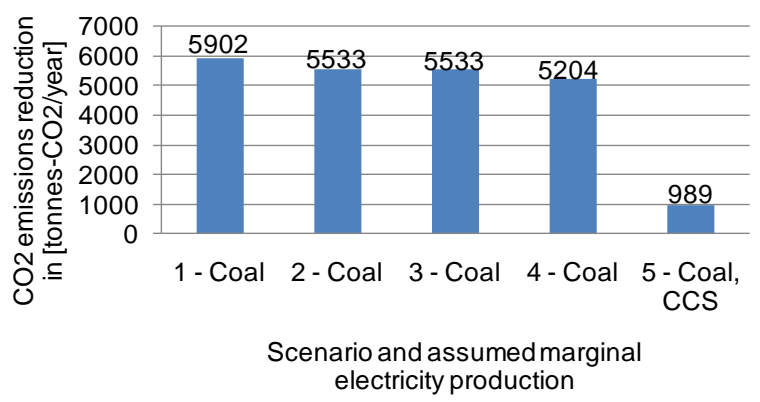

Figure $5 \mathrm{CO}_{2}$ emissions reduction associated with electricity production from excess process heat using ORC unit

\section{Conclusions and Discussion}

In this paper TSA methodology was used to identify the amount of net excess heat from a chemical cluster including the corresponding temperature levels suitable for low temperature heat-to-electricity production by ORC technology. For a more detailed analysis a suitable process stream was selected as heat source. Process simulation was used to determine the best working fluid for the suggested ORC unit, to calculate the net electricity output and the electrical efficiency of the unit. The simulation results were used for preliminary economic assessment and calculation of $\mathrm{CO}_{2}$ emissions reduction potential based on different future energy market scenarios. From the TSA study it was found that there is $192 \mathrm{MW}_{\text {heat }}$ at a temperature range between $84^{\circ} \mathrm{C}$ and $55^{\circ} \mathrm{C}$ available that can potentially be used for ORC applications. It was shown by process simulation that the selected ORC reaches an electrical efficiency of $6.85 \%$ when converting ca. $14 \mathrm{MW}_{\text {heat }}$ into $953 \mathrm{~kW}_{\mathrm{el}}$, using butane as working fluid. Economic assessment of the system shows a strong dependence of profitability to the costs for integration of the ORC unit in the process. Production costs were determined in a range between 70 and $147 € / \mathrm{MWh}$, indicating that at the current prices and without support an ORC project is not feasible and also only two out of seven scenarios showed feasibility without support. Depending on the scenario, pay-back periods between 5.8 to 12.3 years 
assuming low costs of integration. RES-E support and $\mathrm{CO}_{2}$ emissions charge were found to have a strong influence on profitability. Pay-back periods lower than 4.5 years should not be expected at the electricity price and RES-E support levels considered in this study, even if in the future support is granted for this kind of electricity production. Standardisation and technology improvements are expected to have a p ositive effect on the costs of ORC technology, leading to lower electricity production costs and pay-back periods in the future.

\section{References}

[1] R. Hackl, E. Andersson, and S. Harvey, "Targeting for energy efficiency and improved energy collaboration between different companies using total site analysis (tsa)," Chemical Engineering Transactions, vol. 21, pp. 301-306, 2010.

[2] S. Harvey and E. Axelsson, "Scenarios for assessing profitability and carbon balances of energy investments in industry," 2010. [ Online]. Available: http://publications.lib.chalmers.se/cpl/record/index.xsql?pubid=98347. [Accessed: 24Nov-2010].

[3] H. Legman and D. Citrin, "Low grade heat recovery," World cement, vol. 35, no. 4, pp. 111-116, 2004.

[4] P. J. Mago, L. M. Chamra, K. Srinivasan, and C. Somayaji, "An examination of regenerative organic Rankine cycles using dry fluids," Applied Thermal Engineering, vol. 28, no. 8, pp. 998-1007, Jun. 2008.

[5] T. C. Hung, T. Y. Shai, and S. K. Wang, "A review of organic rankine cycles (ORCs) for the recovery of low-grade waste heat," Energy, vol. 22, no. 7, pp. 661-667, Jul. 1997.

[6] B. F. Tchanche, G. Papadakis, G. Lambrinos, and A. Frangoudakis, "Fluid selection for a low-temperature solar organic Rankine cycle," Applied Thermal Engineering, vol. 29, no. 11, pp. 2468-2476, Aug. 2009.

[7] N. B. Desai and S. Bandyopadhyay, "Process integration of organic Rankine cycle," Energy, vol. 34, no. 10, pp. 1674-1686, Oct. 2009.

[8] Opcon, "Emission free electric power," 2010. [ Online]. Available: http://www.opcon.se/www/files/oes/opcon_powerbox_eng.pdf. [Accessed: 07-Dec2010].

[9] G. Pernecker and S. Uhlig, "Low-enthalpy power generation with ORC-turbogenerator, the altheim-project," in GHC BULLETIN, 2002.

[10]Chemical Engineering, "Economic Indicators," Chemical Engineering, vol. 117, no. 7 , pp. 59-60, Jul. 2010.

[11]B. Asp, M. Wiklung, and J. Dahl, Användning av stålindustrins restenergier för elproduktion: Ett effektivt resursutnyttjande för elproduktion. Luleå: Jernkontorets Forskning, 2008.

[12]I. Obernberger, P. Thonhofer, and E. Reisenhofer, "Description and evaluation of the new $1,000 \mathrm{kWel}$ Organic Rankie Cycle process integrated in the biomass CHP plant in Lienz, Austria," Euroheat \& Power, vol. 10, 2002.

[13]R. Vescovo, "ORC recovering industrial waste heat," Cogeneration and On-Site Power Production, vol. 10, no. 2, pp. 53-57, 2009.

[14] S. Harvey and E. Axelsson, Scenarios for assessing profitability and carbon balances of energy investments in industry. Chalmers University of Technology, 2010. 